\title{
Psychotropic drug use among older people in general practice: discrepancies between opinion and practice
}

\author{
Andrea Lasserre, Nadia Younès, Thierry Blanchon, Inge Cantegreil-Kallen, \\ Christine Passerieux, Guy Thomas, Christine Chan-Chee and Thomas Hanslik
}

\begin{abstract}
\section{Background}

The use of psychotropic drugs has increased over recent years in France. GPs are the first prescribers,
\end{abstract} especially for older patients.

Aim

To analyse discrepancies between GPs' opinions and practice when prescribing psychotropic drugs to older patients.

Setting

Postal surveys sent to GPs all over mainland France.

Design of study

Cross-sectional postal study.

\section{Method}

A questionnaire collected data on characteristics of GPs' practices, their opinions about psychotropic drug consumption in older people, and a full description of their last older patient receiving a psychotropic drug and seen last by the GP on that particular day.

\section{Results}

A total of 350 participating GPs saw 2498 patients aged $\geq 65$ years. Among these patients, the prevalence of psychotropic use was $32.1 \%$ (803/2498) for anxiolytics/hypnotics, and $17.5 \%$ for antidepressants (438/2498). A total of $91 \%$ of GPs agreed that it was possible to reduce or stop psychotropic drugs for these patients. Characteristics of 339 patients taking psychotropic drug were reported: $85.8 \%(291 / 339)$ received at least one anxiolytic/hypnotic and $56.9 \%$ (193/339) received at least one antidepressant; there were prescribed for more than 1 year in $68.4 \%$ $(199 / 291)$ and $43.5 \%(84 / 193)$ of the cases respectively. GPs stated that it was possible to reduce or stop anxiolytic/hypnotic drugs for only $27 \%$ (79/291) of these patients. Barriers to doing this were patients' refusal (79\%), and the absence of any local offer of psychotherapy $(73 \%)$ or alternative therapy $(70 \%)$.

\section{Conclusion}

A mismatch exists between GPs' intent (91\%) and practice $(27 \%)$ regarding reduction of psychotropic prescription in individuals aged $\geq 65$ years. The barriers encountered should be examined further to help physicians improve management of psychotropic prescription.

Keywords

antidepressive; anti-anxiety agents; aged; hypnotics and sedatives; mental disorders; psychotropic drugs.

\section{INTRODUCTION}

The consumption of psychotropic drugs is increasing in industrialised countries. ${ }^{1}$ The highest consumption rate is observed in France, with $25 \%$ of the general population taking a psychotropic. The rate is between $3.5 \%$ and $15.5 \%$ in other European countries such as the UK (3.5\%), Germany (5.9\%), Netherlands (7.4\%), Belgium (13.2\%), Italy (13.7\%), and Spain (15.5\%). ${ }^{1-3}$ These discrepancies are not well explained; they could, for example, be related to different organisation of care, such as varying access to psychotherapists. ${ }^{1}$

Psychotropics have the second highest medication sales in France, after analgesics, ${ }^{4}$ and in 2004, $€ 1$ billion were spent on psychotropic medications. ${ }^{5}$ Anxiolytics and hypnotics are the most commonly used drugs in France, with $15-20 \%$ of individuals reporting sporadic use and $10 \%$ regular use of one of them. ${ }^{1,4}$ Antidepressants are the second most

A Lasserre, PhD; T Blanchon, $M D, P h D$; G Thomas, $M D$, PhD; INSERM, U707, Paris, France; UPMC Université Paris 6, UMR S707, Paris, France. T Hanslik, MD, PhD, INSERM, U707, Paris, France; UPMC Université Paris 6, UMR S707, Paris, France; Assistance Publique Hôpitaux de Paris, Hôpital Ambroise Paré, Boulogne Billancourt, France, Université Versailles Saint Quentin en Yvelines, Versailles, France. $N$ Younès, MD, PhD; C Passerieux, MD, Université Versailles Saint Quentin en Yvelines, Versailles, France. I Cantegreil-Kallen, PhD, Hôpital Broca, Paris, France. C Chan-Chee, MD, Institut de Veille Sanitaire, SaintMaurice, France.

Address for correspondence Andrea Lasserre, UMR S707, Faculté de Médecine Pierre et Marie Curie, site Saint Antoine, 27, rue Chaligny, 75571 Paris Cedex 12, France.

E-mail: lasserre@u707.jussieu.fr

Submitted: 9 June 2009; Editor's response: 27 July 2009; final acceptance: 24 September 2009.

(C)British Journal of General Practice

This is the full-length article of an abridged version published in print. Cite this article as: Br J Gen Pract 2010; DOI: 10.3399/bjgp10X483922. 
commonly used drugs, with $10 \%$ of individuals reporting sporadic use and $5 \%$ regular use. 5,6 Consumption is higher in females and increases with age. ${ }^{1,2,6}$

Prescribing psychotropic drugs is part of GPs' daily routine. In France, $60-75 \%$ of prescriptions for psychotropic drugs are from GPs, where $80-92.3 \%$ are prescribed to people older than 65 years. $^{7}$ In the UK, hypnotic treatment is also initiated by GPs in $87.9 \%$ of cases. ${ }^{8}$

For older people, the harms of psychotropic drugs may outweigh their benefits. They have been previously identified as a risk factor for falls,,${ }^{9,10}$ car accidents, ${ }^{11}$ and cognitive disorders. ${ }^{12,13}$ Older people are more vulnerable to the neurological side-effects of these medications because of the changes in their pharmacokinetics and pharmacodynamics related to ageing. ${ }^{14}$

Although the desirability of reducing psychotropic medication to avoid side-effects has been recognised, consumption remains excessive..$^{15,16}$ Potential barriers to reducing psychotropic prescription were previously reported, such as GPs' lack of agreement regarding interpretation or implementation of the clinical guidelines, or difficulty reconciling patients' preferences..$^{16}$ The present study was undertaken to provide more insight into GPs' prescribing patterns for older people. The aim was to investigate GPs' knowledge and opinions about prescription of psychotropics for individuals aged $\geq 65$ years, and to collect patient-based data to describe 'real-life' prescription patterns for psychotropics in this population.

\section{METHOD}

The study was carried out by means of a crosssectional survey among GPs belonging to the 'Sentinelles network' in France. The Sentinelles network is a computerised system comprising 1200 volunteer GPs located throughout France and participating in the ongoing surveillance of 10 health indicators and in ad hoc epidemiological studies. ${ }^{17}$ The 10 health indicators comprise seven infectious diseases (influenza-like illness, acute diarrhoea, mumps, varicella zoster, herpes zoster, male urethritis, Lyme disease), as well as three non-infectious conditions (asthma, suicide attempts, any-cause hospitalisations).

In November 2007, the questionnaire with a return envelope was sent to 967 GPs (those who had previously agreed to participate at least once in the ad hoc epidemiological studies); responses were collected until January 2008. Two reminders were sent if no answer was received; the second included a new questionnaire sent by email. After data collection, a sample of non-responders (randomly selected) was

\section{How this fits in}

Inappropriate use of psychotropic drugs among older patients is an important problem seen in general practice. Confronting, at the same time, GPs' opinions and real practice regarding psychotropic drugs use in older people reveals a gap between opinions and practice for benzodiazepines and for Z-drugs. GPs surveyed in this study suggested some actions for improvements.

contacted to ascertain the reasons for not participating. The postal questionnaire consisted of three parts.

The first part collected characteristics about the GPs (demography and practice), the number of patients aged $\geq 65$ years seen on the GPs' last working day and, for these patients, the reason for consultation and the prevalence of psychotropic use.

The second part assessed GPs' knowledge and opinions about psychotropic drug consumption in individuals aged $\geq 65$ years. GPs were questioned about their knowledge of six recommendations for managing psychotropic treatment issued by the French health authorities (yes/no questions). ${ }^{18}$ Their opinion was sought about psychotropic use in primary care with the following questions: (i) do you sometimes feel pressured to initiate or to renew prescription of anxiolytics/hypnotics for your patients aged over 65 years? (often/sometimes/never); (ii) do you think it is possible to reduce prescription of anxiolytics/hypnotics for patients aged over 65 years? (yes in most cases/yes in some cases/ no, I don't know); and (iii) what kind of actions must be undertaken to reduce prescription of anxiolytics/hypnotics? (four answers were proposed with a four-point scale ranging from 'completely disagree' to 'completely agree': campaigning to inform the general population, increasing access to a psychiatrist, reinforcing GPs' education, or increasing access to psychotherapy).

The third part of the questionnaire investigated patient-based data regarding the characteristics of the last patient aged $\geq 65$ years seen by the GP on that working day and receiving a psychotropic drug. Data were collected regarding: demographics; prescribed psychotropic drugs; duration of treatment (<3 months, 3-12 months, 1-5 years, >5 years); difficulties encountered by GPs in stopping or reducing the dose of a psychotropic drug; and barriers to reducing or stopping treatment. Seven barriers were proposed with a four-point scale ranging from 'completely disagree' to 'completely agree': (i) the patient does not want to stop the treatment; (ii) psychotherapy is not refunded; (iii) psychotherapy is not feasible; (iv) there is no alternative therapy to propose; (v) the risks associated with drug withdrawal are considered 
higher than those related to maintaining treatment; (vi) refusal of drug withdrawal by the patient's relatives and carers; and (vii) lack of awareness of the drug-withdrawal procedure. Benzodiazepines were differentiated according to their duration of action (short-, medium-, or long-acting). ${ }^{18}$ Psychotropic prescription was considered 'inappropriate' if a condition known to increase the risk of an adverse reaction was present: (i) use of a long-acting benzodiazepine; ${ }^{19}$ (ii) benzodiazepine prescription for more than 3 months; $;^{17,20,21}$ and/or (iii) concomitant use of three or more psychotropic drugs. . $2,23^{2}$

Statistical analyses were performed using the statistical package R-2.6.1. Frequency distribution, cross-tabulation, and $\chi^{2}$ tests were used to analyse categorical data. Significance was set at $P<0.05$.

\section{RESULTS}

\section{Characteristics of GP and study populations}

Questionnaires were returned by 350 GPs, which represents a response rate of $36.1 \%$ (350/967). Among the non-responders, the reason for nonparticipation was a lack of time to answer $(90.1 \%$, $128 / 142$ ) or lack of interest in the objective of the study $(8.9 \%, 16 / 142)$. Responders practised in all 22 regions of the country, had been practising for an average of 16 years, were predominantly male $(84.8 \%)$, and had a mean age of 44 years. Participating GPs were significantly younger than non-responding GPs (44 years versus 55 years, $P<0.001$ ); they did not significantly differ in terms of sex or location of practice (rural or urban areas).

On their last working day, responder GPs saw 2498 patients aged $\geq 65$ years. GPs declared that these older patients were consulting for a physical problem, a psychological problem, or both, in 55.8\% (1394/2498), 37\% (924/2498), and 7.2\% (180/2498) of cases respectively. These patients were taking an anxiolytic/hypnotic in $32.1 \%$ (803/2498) of cases, antidepressants in $17.5 \%(438 / 2498)$ of cases, and antipsychotic treatment in $8.1 \%(202 / 2498)$ of cases.

\section{Table 1. GPs' opinions about prescriptions for psychotropic drugs among patients aged $\geq 65$ years.}

\begin{tabular}{lc} 
Opinion & $n(\%)$ \\
\hline Do you sometimes feel pressured to initiate or renew anxiolytic/hypnotic & \\
prescriptions for your patients aged 65 years or over? & $234(67.4)$ \\
Often & $103(29.7)$ \\
Sometimes & $10(2.9)$ \\
Never & \\
\hline Do you think it is possible to reduce prescription of anxiolytics/hypnotics & \\
for patients aged 65 years or over? & $67(19.3)$ \\
Yes, in most cases & $247(71.2)$ \\
Yes, in some cases & $30(8.6)$ \\
No & $3(0.9)$ \\
\hline I don't know & \\
\hline
\end{tabular}

\section{GPs' opinions about psychotropic use for individuals aged $\geq 65$ years}

When asked if they knew the six national guidelines for managing people with anxiety and/or insomnia, $22 \%(191 / 349)$ of GPs declared that they did, while $82 \%$ knew at least one of these guidelines. One of the guidelines, 'How to stop benzodiazepine and benzodiazepine-related drugs (Z-drugs) among older patients', ${ }^{18}$ was reported to be the best known $(70 \%$ of GPs).

Pressure by patients to initiate or renew prescription of anxiolytics/hypnotics had previously been felt by $97.1 \%$ of GPs (Table 1). However, $90.5 \%$ declared that it was possible to reduce or stop treatment for their patients. GPs felt that more information should be distributed to the general population (84\%) as well as to physicians (80\%). Lastly, GPs agreed that greater access to psychiatrists could help to reduce prescription of psychotropic drugs (Figure 1).

\section{Psychotropic consumption: patient-based data} Psychotropic consumption of 339 patients is described in Table 2. Patients were aged a mean of 77.3 years $(S D=7.5)$, mostly female $(70.8 \%$, $240 / 339)$, and were living alone (46.5\%, 157/338), with their family $(40.8 \%, 138 / 338)$, or in an institution (12.8\%, 43/338).

Overall, 195 of the 339 patients were taking at least one anxiolytic, 140 patients were taking at least one hypnotic, and 193 patients were taking at least one antidepressant. Anxiolytics were the most commonly used drugs (57.5\%, 195/339), with a proportion of exclusive users of $22.1 \%$ (75/339).

The anxiolytics most frequently prescribed were lorazepam $(22.6 \%, 44 / 195)$, bromazepam $(21.0 \%$, 41/195), and alprazolam (13.3\%, 26/195). Hypnotics were used by $41.3 \%$ of patients (140/339), with a proportion of exclusive users of $15.9 \%$ (54/339). The most frequently prescribed hypnotics were zolpidem (57.1\%, 80/140) and zopiclone $(27.8 \%, 39 / 140)$. Antidepressants were used by $56.9 \%$ of patients receiving a psychotropic drug (193/339), with a proportion of exclusive users of $14.7 \%$ (50/339). The types of antidepressants reported were specific serotonin reuptake inhibitors $(52.8 \%, 102 / 193)$, specific noradrenaline (norepinephrine) reuptake inhibitors (15.5\%, 30/193), tianeptine (12.9\%, $25 / 193)$, mianserine $(11.4 \%, 22 / 193)$, and tricyclics (7.3\%, 14/193).

The most frequent drug combinations were anxiolytics with antidepressants (12.6\%, 74/339), followed by antidepressants combined with hypnotics (11.8\%, 40/339). Among the 291 patients who were under an anxiolytic or hypnotic drug, the treatment duration was over 1 year in $68.4 \%$ of 


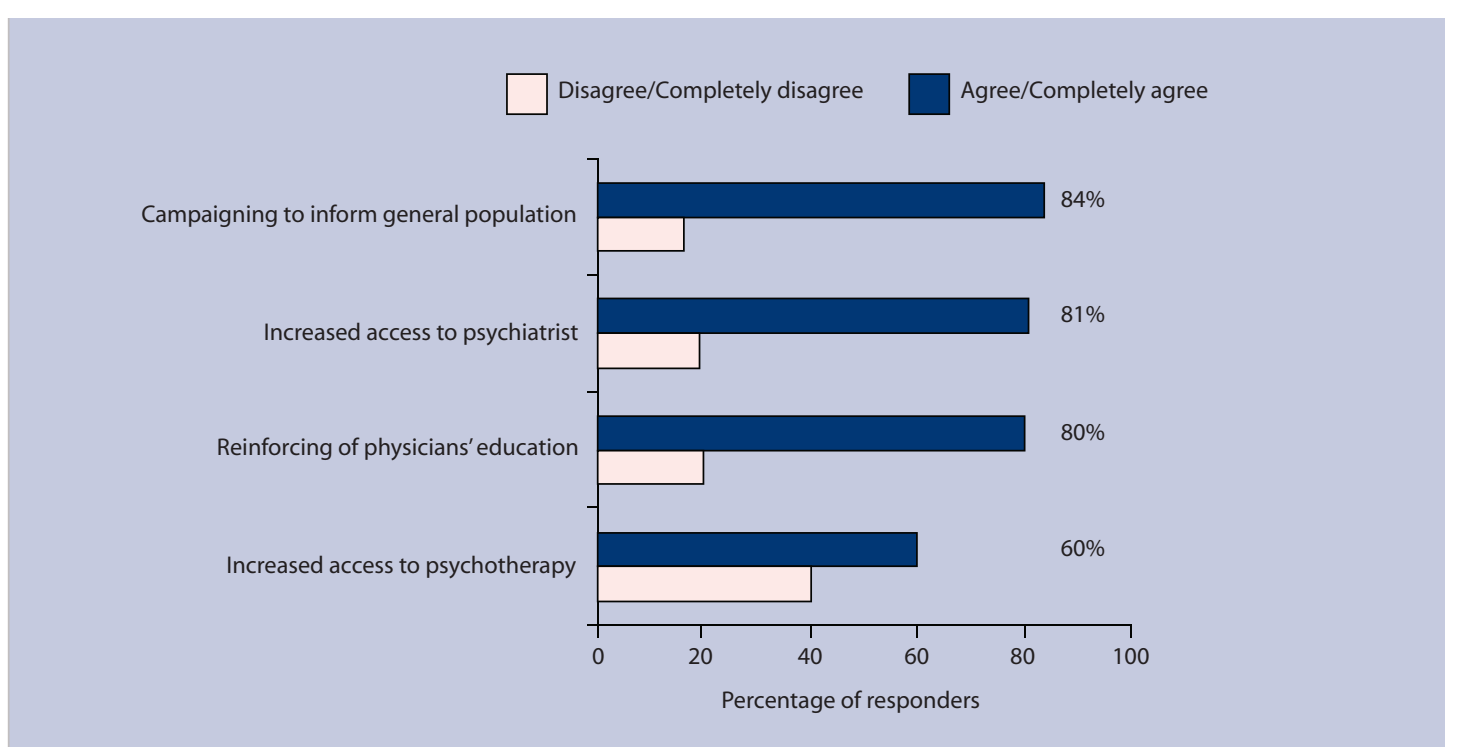

cases (199/291). The main indication for anxiolytics or hypnotics was anxiety $(71.8 \%, 209 / 291)$, chronic insomnia $(60.1 \%, 175 / 291)$, and/or depression (31.9\%, 93/291). Among the 193 patients who were taking antidepressants, the treatment duration was over 1 year in $43.5 \%$ of cases (84/193; Table 2). They were prescribed for depression $(93.3 \%, 180 / 193)$ and/or anxiety $(45.1 \%, 87 / 193)$.

Psychotropic drug use was inappropriate in $84.3 \%$ $(285 / 339)$ of cases, owing to long-acting benzodiazepine use $(7.6 \%, 26 / 339)$, concomitant use of three or more psychotropic drugs $(8.6 \%$, $29 / 339$ ), or the use of benzodiazepines or Z-drugs for more than 3 months $(84.2 \%, 285 / 339)$.

GPs stated that it was impossible to reduce or stop anxiolytic or hypnotic treatment for $57 \%$ of patients (166/291), whereas $27.1 \%(79 / 291)$ agreed that it could be possible. Forty-six GPs had no opinion. GPs rated that $68.1 \%(199 / 291)$ of the patients were physically dependent on their anxiolytics/hypnotics, $32.9 \%$ (96/291) were psychologically dependent, and $30.4 \%$ (198/291) physically and psychologically dependent. Dependence on antidepressants was estimated to be $20.7 \%$ (40/193), 32.4\% (41/193), and $15.5 \%$ (30/193) for physical, psychological, or both types of dependence respectively.

Barriers to reducing the dosage or to stopping anxiolytics/hypnotics for these patients are presented in Figure 2. The principal barriers reported were patients' refusal (79\%), absence of reimbursement of psychotherapy $(79 \%)$, or no local offer of psychotherapy available (73\%), and absence of any other alternative therapy $(70 \%)$.

\section{DISCUSSION}

\section{Summary of main findings}

This study confirmed the high rate of very long-term prescription (defined as $>2$ years in duration), and combined use of psychotropic medication among older patients seen in general practice. While 90.5\% of GPs stated that it was possible to reduce or stop psychotropic drugs in most older patients, only $27.1 \%$ reported the feasibility of doing so when facing their patients. These findings illustrate a mismatch between GPs' opinions about psychotropic prescription and the reality of practice. According to GPs, the principal barriers to reducing or stopping anxiolytic/hypnotic drugs were patient refusal and the unavailability of psychotherapy or alternative therapies. GPs agreed that more

\section{Table 2. Psychotropic consumption in} 339 patients aged $\geq 65$ years.

\begin{tabular}{lc} 
Overall use, $n=339$ & $n(\%)$ \\
Anxiolytics & $195(57.5)$ \\
Hypnotics & $140(41.3)$ \\
Antidepressants & $193(56.9)$ \\
\hline Exclusive use, $n=339$ & $179(52.8)$ \\
Anxiolytics & $75(22.1)$ \\
Hypnotics & $54(15.9)$ \\
Antidepressants & $50(14.7)$ \\
\hline Combined use, $n=339$ & $160(47.2)$ \\
Anxiolytics + antidepressants & $74(21.8)$ \\
Hypnotics + antidepressants & $40(11.8)$ \\
Anxiolytics + hypnotics & $17(5.0)$ \\
Antidepressants + anxiolytics + hypnotics & $29(8.0)$ \\
\hline Duration of all the treatment reported & \\
Anxiolytics $+/$ hypnotics, $n=291$ & \\
$<3$ months & $44(15.1)$ \\
$3-12$ months & $48(16.5)$ \\
$1-5$ years & $88(30.2)$ \\
$>5$ years & $111(38.2)$ \\
Antidepressants, $n=189$ & \\
$<3$ months & $48(25.4)$ \\
$3-12$ months & $57(30.1)$ \\
$1-5$ years & $50(26.4)$ \\
$>5$ years & $34(17.9)$ \\
\hline
\end{tabular}

Figure 1. GPs' general opinions on ways to reduce anxiolytic/hypnotic prescriptions among patients aged $\geq 65$ years. 
Figure 2. Barriers to reduce or stop anxiolytic or hypnotic drugs in patients aged $\geq 65$ years.

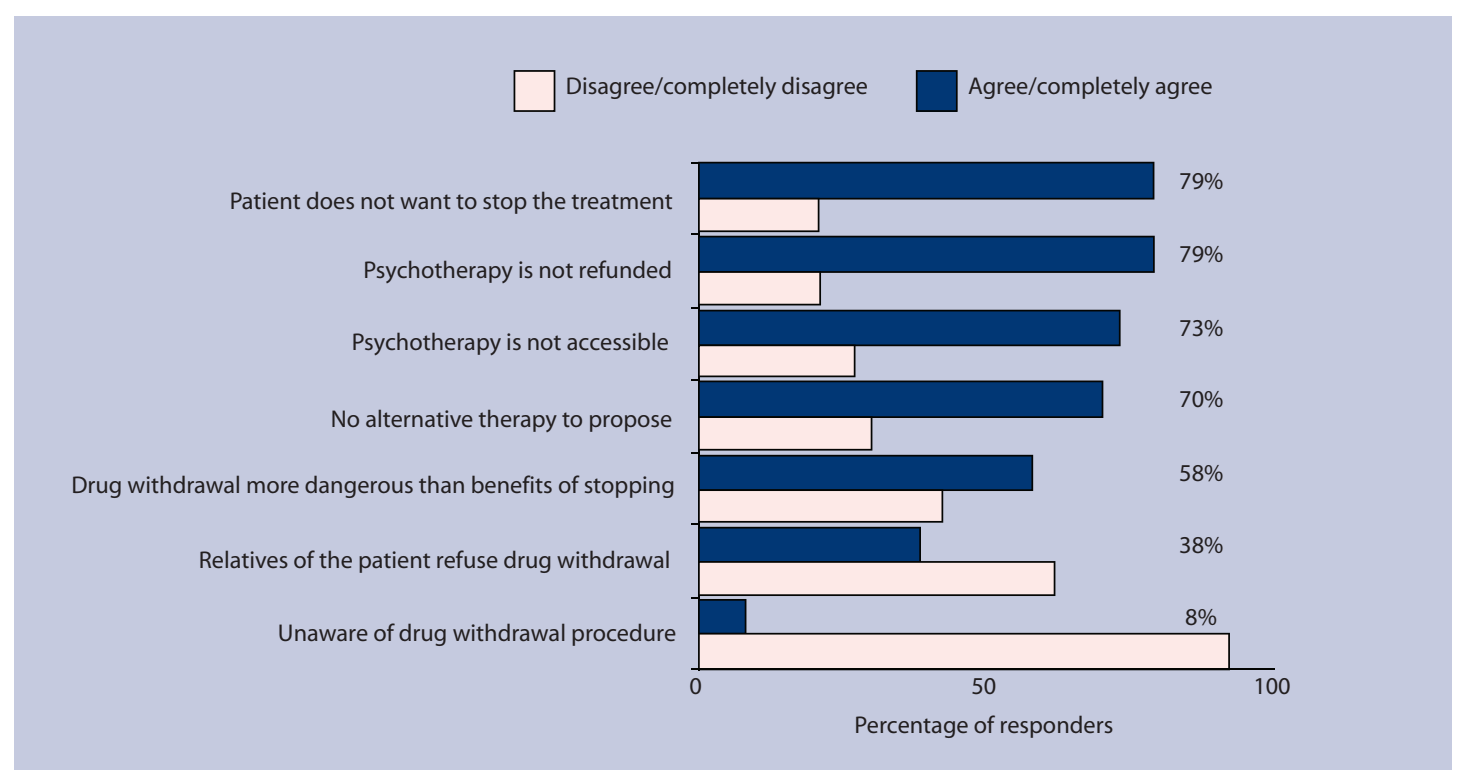

information must be provided to educate the public as well as physicians on this matter.

\section{Strengths and limitations of the study}

The participation rate of $36.1 \%$ is within the range of results from most surveys conducted in general practice. ${ }^{8,24-26}$ There may be a selection bias because GPs in the Sentinelles network are younger than the overall population of GPs in France. Moreover, GPs who participated in this study might be more concerned about mental health problems that nonresponders and their practices may, therefore, differ. However, the daily number of patients seen by the participating GPs is not different from the number seen daily by all French GPs, ${ }^{27}$ and the rate of psychotropic use reported here is similar to the rates previously described in other general practice settings in France. ${ }^{1,2,4,28}$

An additional limitation may have been introduced by only offering the GPs closed questions. Some GPs spontaneously made comments pointing out other reasons for overprescription of psychotropics. In addition, GPs rated their knowledge of the French guidelines for treating older individuals with psychotropic drugs using 'yes/no' answers, so this information must be interpreted with some caution because no check was done on whether the stated knowledge was accurate. Finally, the survey does not present data about diagnosis (and the adequacy of treatment according to the diagnosis) or patients' opinions.

\section{Comparison with existing literature}

The present study confirms that almost one of three patients aged $\geq 65$ years and seen in French general practice receives an anxiolytic or hypnotic prescription, and one of five patients receives an antidepressant prescription. These results are in accordance with the results of previous studies conducted in France..$^{1-4,6,12,28-34}$

In France, benzodiazepines are somewhat more frequently prescribed than Z-drugs, compared to other countries. In Sweden and in the UK, Z-drugs are more frequently prescribed than the conventional benzodiazepines. ${ }^{35}$ However, both treatments (benzodiazepines and Z-drugs) should be used with caution. ${ }^{36,37}$

The prevalence of inappropriate psychotropic drug use is comparable to the percentages found in Sweden, specifically regarding the use of long-acting benzodiazepines or the concomitant use of three or more psychotropic drugs. ${ }^{35}$ The present study highlights the excessive duration of psychotropic treatments, particularly for benzodiazepines and Zdrugs. Although antidepressants can be indicated for long-term treatment, ${ }^{38}$ hypnotics are not recommended for longer than 1 month, and anxiolytics are recommended for no longer than 3 months. ${ }^{16,21,39-42}$

GPs' opinions and knowledge about psychotropic drug prescription in older patients have rarely been explored. In the present study, $91 \%$ of GPs were optimistic about the possibility of reducing or stopping anxiolytics and hypnotics. In reality, only $27 \%$ of GPs admitted it was possible when facing their patients. This mismatch between 'theoretical' and 'real-world' practice reveals that knowledge of the guidelines is insufficient, as reported in the literature. ${ }^{41-43}$

Several factors have been identified to explain inappropriate prescribing of psychotropics in older people: (i) GP-related barriers, including lack of knowledge; (ii) confusion due to the lack of a consensus defining inappropriate psychotropic use; (iii) difficulties in re-addressing inappropriate 
medication started by a previous provider; (iv) the number of prescribers and pharmacies involved in patient care; (v) inappropriate attitudes towards ageing (ageism); and (vi) cost issues. ${ }^{44}$ Patients may also contribute to the problem by insistently demanding an inappropriate medication. ${ }^{45-47}$

In the present study, some GPs offered additional comments about prescription barriers that were different from those proposed in the questionnaire; these included: 'The best way to avoid withdrawal problems is to avoid initial prescription!', 'Incentives for psychotropic prescription through pharmaceutical marketing should be stopped', and 'Psychotropics are impossible to stop mainly for patients with a difficult social life (loneliness, poverty, living in a deprived neighbourhood)'. These last comments confirm that current management of psychological and physical troubles deserves more attention, ${ }^{44,45}$ and that psychotropic consumption is probably not simply a consequence of a GP prescription, but is also a social issue.

\section{Implications for future research and clinical practice}

More appropriate use of psychotropic prescription drugs is a key element in improving disease management for older patients in general practice. GPs suggested three areas that should be targeted: (i) implementing educational programmes to increase patients' awareness of the risks related to long-term use of psychotropics; (ii) creating work groups to support drug withdrawal in primary care; and (iii) applying behavioural treatments, such as cognitive therapy, sleep education, sleep hygiene, and muscle relaxation. ${ }^{45-48}$ The effectiveness and acceptance of these psychological interventions for mental health problems in older people have been recently evidenced, even if not widely promoted in daily practice. ${ }^{49-51}$

Collaborative care between GPs and psychiatrists could also encourage appropriate prescriptions. Another area that could probably be targeted is the difference between whether the medication could be stopped or whether there is clinical evidence that it should be stopped. Although there is clear evidence of the risks associated with long-term use of hypnotic/anxiolytic drugs, stopping these treatments may also expose patients to rebound anxiety, withdrawal syndrome, and the social consequences of untreated anxiety disorders. ${ }^{52-54}$ Thus, efforts to reduce the risks associated with long-term use of psychotropics should be balanced with the risks associated with psychotropic withdrawal.

This study has evidenced an important mismatch between GPs' opinions about psychotropic prescription and the reality of practice. Reconciliation of theory and practice is needed and should be further examined. To help GPs to reduce psychotropic consumption and prescription, specific education of the general public and physicians is needed, and increased access to non-pharmacological treatment and collaborative care with a psychiatrist could be evaluated.

\section{Funding body}

The study was supported by the French Institute for Public Health Surveillance (InVS, Saint Maurice, France).

Ethics committee

Not applicable for this study.

Competing interests

The authors have stated that there are none.

Acknowledgements

We are grateful to all participating physicians.

Discuss this article

Contribute and read comments about this article on the Discussion Forum: http://www.rcgp.org.uk/bjgp-discuss

\section{REFERENCES}

1. Gasquet I, Nègre-Pagès L, Fourrier A, et al. Psychotropic drug use and mental psychiatric disorders in France: results of the general population ESEMeD/MHEDEA 2000 epidemiological study. Encephale 2005; 31(2): 195-206.

2. Alonso J, Angermeyer MC, Bernert S, et al. Psychotropic drug utilization in Europe: results from the European Study of the Epidemiology of Mental Disorders (ESEMeD) project. Acta Psychiatr Scand Suppl 2004; (420): 55-64.

3. Ohayon M, Lader MH. Use of psychotropic medication in the general population of France, Germany, Italy and United Kingdom. J Clin Psychiatry 2002; 63(9): 817-825.

4. Lecadet J, Vidal P, Baris B, et al. Médicaments psychotropes: consommation et pratiques de prescription en France métropolitaine [in French]. Rev Med Ass Maladie 2003; 34(1): 75-84.

5. Briot M. Assemblée Nationale No 3187. Rapport sur le bon usage des médicaments psychotropes. [Adequate use of psychotropic treatments, a report]. http://www.assemblee-nationale.fr/12/rap-off/i3187.asp (accessed 6 Nov 2009).

6. Ritchie K, Artero S, Beluche I, et al. Prevalence of DSM-IV psychiatric disorder in the French elderly population. Br J Psychiatry 2004; 184: $147-52$.

7. Olié JP, El Omari F, Spadone C, Lépine JP. Results of a survey about antidepressant use in the general French population. Encephale 2002; 28(5): 411-417.

8. Iliffe S, Curran HV, Collins R, et al. Attitudes to long-term use of benzodiazepine hypnotics by older people in general practice: findings from interviews with service users and providers. Aging Ment Health 2004; 8(3): 242-248.

9. Berdot S, Bertrand M, Dartigues JF, et al. Inappropriate medication use and risk of falls: a prospective study in a large community elderly cohort. BMC Geriatr 2009; 9: 30-40.

10. Souchet E, Lapeyre-Mestre M, Montastruc JL. Drug related falls: a study in the French Pharmacovigilance database. Pharmacoepidemiol Drug Saf 2005; 14(1): 11-16.

11. McGwin G Jr, Sims RV, Pulley L, Roseman JM. Relations among chronic medical conditions, medications, and automobile crashes in the elderly: a population-based case-control study. Am J Epidemiol 2000; 152(5): 424-431.

12. Paterniti S, Dufouil C, Alperovitch A. Long-term benzodiazepine use and cognitive decline in the elderly: the Epidemiology of Vascular Aging Study. J Clin Psychopharmacol 2002; 22(3): 285-293.

13. Allard J, Artero S, Ritchie K. Consumption of psychotropic medication in the elderly: a re-evaluation of its effect on cognitive performance. Int J Geriatr Psychiatry 2003; 18(10): 874-878.

14. Greenblatt DJ, Harmatz JS, Shader RI. Clinical pharmacokinetics of anxiolytics and hypnotics in the elderly. Part II: Therapeutic considerations. Clin Pharmacokinet 1991; 21(4): 262-273.

15. Haute Autorité de Santé. Press release 16 October 2006. Améliorer la prescription des psychotropes chez la personne âgée : un an après, un 
bilan d'étape encourageant. [Guideline to improve psychotropics prescription in elderly.] http://www.has-

sante.fr/portail/jcms/c_702209/ (accessed 6 Nov 2009).

16. Straand J, Rokstad K. Elderly patients in general practice: diagnoses, drugs and inappropriate prescriptions. A report from the Møre \& Romsdal Prescription Study. Fam Pract 1999; 16(4): 380-388.

17. Flahault A, Blanchon T, Dorléans Y, et al. Virtual surveillance of communicable diseases: a 20-year experience in France. Stat Methods Med Res 2006; 15(5): 413-421.

18. Haute Autorité de Santé. Modalités d'arrêt des benzodiazépines et médicaments apparentés chez le patient âgé. [Guideline to stop benzodiazepines in the elderly]. http://www.hassante.fr/portail/jcms/c_601509 (accessed 6 Nov 2009).

19. Linjakumpu T, Hartikainen S, Klaukka T, et al. Psychotropics among the home-dwelling-elderly: increasing trends. Int J Geriatr Psychiatry 2002; 17(9): 874-83.

20. Fick DM, Cooper JW, Wade WE, et al. Updating the Beers criteria fo potentially inappropriate medication use in older adults: results of a US consensus panel of experts. Arch Intern Med 2003; 163(22): 2716-2724.

21. Mort JR, Aparasu RR. Prescribing of psychotropics in the elderly: why is it so often inappropriate? CNS Drugs 2002; 16(2): 99-109.

22. Johnell K, Fastbom J. The use of benzodiazepines and related drugs amongst older people in Sweden: associated factors and concomitant use of other psychotropics. Int J Geriatr Psychiatry 2009; 24(7): 731-738.

23. Klarin I, Wimo A, Fastbom J. The association of inappropriate drug use with hospitalisation and mortality: a population-based study of the very old. Drugs Aging 2005; 22(1): 69-82.

24. Telford R, Hutchinson A, Jones R, et al. A. Obstacles to effective treatment of depression: a general practice perspective. Fam Pract 2002; 19(1): 45-52.

25. Nutting PA, Rost K, Dickinson M, et al. Barriers to initiating depression treatment in primary care practice. J Gen Intern Med 2002; 17(2): 103-111.

26. Lasserre A, Pelat C, Guéroult V, et al. Urinary incontinence in French women: prevalence, risk factors, and impact on quality of life. Eur Urol 2009; 56(1): 177-183.

27. Labarthe G. Visiting the general practices: an etiological study [in French]. Etudes et résultats 2004; 315: 1-11. http://www.sante.gouv.fr/drees/etude-resultat/er-pdf/er315.pdf (accessed 6 November 2009).

28. Lépine JP, Gasquet I, Kovess V, et al. Prevalence and comorbidity of psychiatric disorders in the French general population. Encephale 2005; 31(2): 182-194.

29. Cavalié P, de Calan C. Report: Evolution 1994-2004 of medicaments sales in France [in French]. Saint-Denis, France: Agence Française de Sécurité Sanitaire des Produits de Santé, 2006.

30. Lechevallier-Michel N, Berr C, Fourrier-Reglat A. Incidence and characteristics of benzodiazepine use in an elderly cohort EVA study. Therapie 2005; 60(6): 561-566.

31. Haute Autorité de Santé, Legrain S. Consommation Médicamenteuse chez le Sujet Agé [in French]. http://www.anaes.fr/anaes/PresMec.nsf (accessed 6 Nov 2009).

32. Olffson M, Marcus SC, Pincus HA, et al. Antidepressant prescribing practices of outpatient psychiatrist. Arch Gen Psychiatry 1998; 55(4): 310-316.

33. Paterniti S, Bisserbe JC, Alperovitch A. Psychotropic drugs, anxiety and depression in the elderly population. The EVA study. Rev
Epidemiol Santé Publique 1998; 46(4): 253-262.

34. Pélissolo A, Boyer P, Lépine JP, Bisserbe JC. Epidemiology of the use of anxiolytic and hyonotic drugs in France and in the world. Encephale 1996; 22(3): 181-190.

35. Siriwardena AN, Qureshi MZ, Dyas JV, et al. Magic bullets for insomnia? Patients' use and experiences of newer (Z-drugs) versus older (benzodiazepine) hypnotics for sleep problems in primary care. Br J Gen Pract 2008; 58(551): 417-422.

36. Hypnotic dependence: zolpidem and zopiclone too. Prescrire Int 2001; 10(51): 15.

37. What's wrong with prescribing hypnotics? Drug Ther Bull 2004; 42(12): 89-93.

38. Rajji TK, Mulsant BH, Lotrich FE, et al. Use of antidepressants in latelife depression. Drugs Aging 2008; 25(10): 841-853.

39. Ribeiro CS, Azevedo RC, Silva VF, Botega NJ. Chronic use of diazepam in primary healthcare centers: user profile and usage pattern. Sao Paulo Med J 2007; 125(5): 270-274.

40. Simon GE, Ludman EJ. Outcome of new benzodiazepine prescriptions to older adults in primary care. Gen Hosp Psychiatry 2006; 28(5): 374-378.

41. Saastamoinen L, Enlund H, Klaukka T. Repeat prescribing in primary care: a prescription study. Pharm World Sci 2008; 30(5): 605-609.

42. Siriwardena AN, Qureshi Z, Gibson S, et al. GPs' attitudes to benzodiazepine and ' $Z$-drug' prescribing: a barrier to implementation of evidence and guidance on hypnotics. Br J Gen Pract 2006; 56(533): 964-967.

43. Wexler RK, Elton T, Taylor CA, et al. Physician reported perception in the treatment of high blood pressure does not correspond to practice. BMC Fam Pract 2009; 10: 23-28.

44. Sim MG, Khong E, Wain TD. The prescribing dilemma of benzodiazepines. Aust Fam Physician 2007; 36(11): 923-926.

45. Bain KT. Management of chronic insomnia in elderly persons. Am J Geriatr Pharmacother 2006; 4(2): 168-192.

46. Benca RM. Diagnosis and treatment of chronic insomnia: a review. Psychiatr Serv 2005; 56(3): 332-343.

47. Kamel NS, Gammack JK. Insomnia in the elderly: cause, approach, and treatment. Am J Med 2006; 119(6): 463-469.

48. Woodward M. Hypnotics. Options to help your patients stop. Aust Fam Physician 2000; 29(10): 939-944.

49. Stanley MA, Wilson NL, Novy DM, et al. Cognitive behavior therapy for generalized anxiety disorder among older adults in primary care: a randomized clinical trial. JAMA 2009; 301(14): 1460-1467.

50. Yassuda MS, Nunes PV. Innovative psychosocial approaches in old age psychiatry. Curr Opin Psychiatry 2009; 22(6): 527-531.

51. Thorp SR, Ayers CR, Nuevo R, et al. Meta-analysis comparing different behavioral treatments for late-life anxiety. Am J Geriat Psychiatry 2009; 17(2): 105-115.

52. Spiegel DA. Psychological strategies for discontinuing benzodiazepine treatment. J Clin Psychopharmacol 1999; 19(6): 17S-22S.

53. Morin CM, Bastien C, Guay B, et al. Randomized clinical trial of supervised tapering and cognitive behavior therapy to facilitate benzodiazepine discontinuation in older adults with chronic insomnia. Am J Psychiatry 2004; 161(2): 332-342.

54. Lemoine P, Kermadi I, Garcia-Acosta S, et al. Double-blind, comparative study of cyamemazine vs. bromazepam in the benzodiazepine withdrawal syndrome. Prog Neuropsychopharmacol Biol Psychiatry 2006; 30(1): 131-137. 